\title{
Cadmium and lead accumulate in the deciduous teeth of children with celiac disease or food allergies
}

\author{
Bogusława Orzechowska-Wylęgała, Anna Obuchowicz, \\ Piotr Malara, Agnieszka Fischer, Barbara Kalita \\ Received: 1 November 2010 / Accepted: 19 January 2011 / Published online: 18 May 2011 \\ (C) The Author(s) 2011. This article is published with open access at Springerlink.com
}

\begin{abstract}
The objective of this study was to examine the relative levels of cadmium, lead and calcium in deciduous teeth of children with celiac disease or food allergies from an industrial area of Poland compared to healthy controls. Using flame atomic absorption spectrometry it was found that children with celiac disease and food allergies had significantly higher lead/calcium and cadmium/calcium ratios in deciduous teeth than healthy controls.
\end{abstract}

Keywords: Teeth, deciduous, Dental enamel, Cadmium, Lead, Spectrophotometry, Atomic absorption

\section{Introduction}

Hard tooth tissue (enamel, dentin and root cement) consists of several minerals with calcium being the main macro-mineral. Minerals of physiological importance as well as toxic metals can bioaccumulate in calcified tissues, i.e., teeth and bone tissues [1]. Hard tooth tissues are distinguished by their limited ability to release accumulated elements into systemic fluids, therefore, teeth provide ideal biological samples for the evaluation of long-term environmental exposure to toxic metals. The mineral and metal contents of teeth reflect the overall content in the whole body [2, 3] and tooth samples have been used to evaluate the environmental exposure of a body to lead and cadmium $[4,5]$. The present study

B. Orzechowska-Wylęgała $(\bowtie) \cdot$ P. Malara

Department of Cranio-Maxillo-Facial Surgery, Medical University of Silesia, Filarowa 5A, 40-565, Katowice, Poland

e-mail: boguslawa.wylegala@gmail.com

A. Obuchowicz $\cdot$ B. Kalita

Department of Pediatrics and the Pediatric Ward of

Gastroenterology, Medical University of Silesia, Bytom, Poland

A. Fischer

Department of Toxicology, Medical University of Silesia,

Sosnowiec, Poland examined the content of these metals in deciduous teeth. These teeth are readily available and their analysis can reflect exposure to toxic metals from the time that odontogenesis begins in the fetal period to when the tooth is lost. However, toxic heavy metals which accumulate in teeth remain in a dynamic balance with normal tooth components, for example heavy metals can replace calcium in hydroxyapatite crystals which are basic structural units of calcified tissues. Therefore, evaluation of cadmium and lead levels in tooth hard tissues should be based not only on the absolute content of these metals but also on the ratio of these metals to calcium. Such ratios are more representative of the relative changes in the levels of accumulated metals [6, 7].

While a variety of factors may influence the content of heavy metals in hard tooth tissues the research focused on systemic diseases which require long-term treatment with restrictive diets. In pediatric patients such diseases include celiac disease and food allergy conditions [8-10]. The long term implementation of restrictive diets has been linked to mineral deficiency in children as well as quantitative and/or qualitative changes in the mineral content of bone and hard tooth tissue. These alterations may result in increased accumulation of toxic metals, such as lead, cadmium, strontium, mercury and arsenic in the body $[11,12]$.

The aim of the present study was to evaluate the levels of selected toxic metals, cadmium and lead, in the deciduous teeth of children 7-11 years of age with celiac disease or food allergies who live in the Upper Silesia region in Poland. This region is characterized by a large concentration of heavy industry, such as coal mining and steel production, resulting in significant environmental pollution. To the knowledge of the authors, there are no previously published data on the toxic metal content in teeth of children with celiac disease or food allergies. 


\section{Materials and methods}

The study protocol was consistent with the tenets of the Declaration of Helsinki.

\section{Patient population}

The study material comprised 150 deciduous teeth from children aged 7-11 years of both genders, including 30 deciduous teeth of children with celiac disease, 60 deciduous teeth of children with food allergies (IgE-dependent cow's milk protein and various other food allergens) and 60 deciduous teeth of healthy children. Table 1 shows the percentage of the various deciduous teeth (incisors, canines, and molars) examined in each group of children.

All children resided in the industrial area of Upper Silesia, Poland, many living in cities. Celiac disease and food allergies were diagnosed before the age of 4 years. Children with celiac disease were maintained on a gluten-free diet and children with food allergies were on a diet without milk or other food allergens which were excluded according to individual recommendations.

\section{Metal analysis}

Teeth without caries, with the resorbed roots or lost in the period of natural tooth exchange were analyzed. Teeth with cavity fillings were not included in the study. The deciduous teeth from children with celiac disease or food allergies were supplied by the parents to the Department of Pediatrics and the Pediatric Ward of Gastroenterology at Medical University of Silesia (MUS) in Bytom, Poland. The teeth from healthy children were obtained from Professor Cieslik of the Department of Cranio-Maxillo-Facial Surgery of MUS in Katowice, Poland.

Before analyses the soft tissue was cleaned off the extracted teeth, the tartar was removed, the teeth were washed several times with double-distilled water, dried at room temperature, minced and mineralized with spectrally clean nitric acid (Merck. KGaA. Darmstadt, Germany). The cadmium, lead and calcium levels in teeth were measured using the flame atomic absorption spectrophotometry method with a Pye Unicam SP-9 (Philips ASS, Cambridge, UK) and an acetylene and air flame. The wavelengths were $217 \mathrm{~nm}$ for lead, $228.8 \mathrm{~nm}$ for cadmium and $422.7 \mathrm{~nm}$ for calcium. The analyses were performed in the Department of Toxicology of the College of Pharmacy of MUS. The lead/calcium and cadmium/calcium ratios were calculated by the mean logarithm method.

\section{Statistical analysis}

The results were statistically analyzed using Anova and the Dunnett's post hoc test. A two-tailed p value of less than 0.05 was considered to be statistically significant.

\section{Results}

The levels of each metal in the deciduous teeth and lead/ calcium and cadmium/calcium ratios are provided in Table 2 and Fig. 1. The deciduous teeth in children with celiac disease contained significantly higher levels of cadmium than those of children with food allergies or healthy controls. Deciduous teeth in children with food allergies had lower lead levels as compared to those levels in children with celiac disease. Lead levels in the deciduous teeth of children with food allergies tended to be higher than those in controls; however, the differences were not statistically significant. The deciduous teeth of children with celiac disease and food allergies contained significantly lower levels of calcium than those in healthy children. The lead/calcium and cadmium/calcium ratios were significantly higher in deciduous teeth of children with celiac disease and food allergies as compared to healthy controls.

Table 1 The percentage of each tooth type in the groups of patients included in the study

\begin{tabular}{|c|c|c|c|}
\hline \multirow[t]{2}{*}{ Type of tooth } & \multicolumn{3}{|c|}{ Children enrolled in the study (groups) } \\
\hline & Celiac disease & Food allergies & Healthy controls \\
\hline Incisor teeth & $50 \%$ & $55 \%$ & $43.4 \%$ \\
\hline Canine teeth & $20 \%$ & $18.3 \%$ & $23.3 \%$ \\
\hline Molar teeth & $30 \%$ & $26.7 \%$ & $33.3 \%$ \\
\hline
\end{tabular}

Table 2 Content of lead, cadmium and calcium in the deciduous teeth of children with celiac disease and food allergies as compared to healthy controls. (Data are mean \pm standard deviation)

\begin{tabular}{l|lll}
\hline \multirow{2}{*}{ Metal } & Tooth metal content & & \multicolumn{2}{c}{ Control } \\
\cline { 2 - 4 } & Celiac disease & Food allergies & $4.19 \pm 1.66$ \\
\hline Lead $(\mu \mathrm{g} / \mathrm{g})$ & $5.42 \pm 2.02^{\mathrm{a}}$ & $4.49 \pm 1.31$ & $0.04 \pm 0.03$ \\
\hline Cadmium $(\mu \mathrm{g} / \mathrm{g})$ & $0.11 \pm 0.05^{\mathrm{a}}$ & $0.05 \pm 0.03$ & $48300 \pm 6.46$ \\
\hline Calcium $(\mathrm{mg} / \mathrm{g})$ & $43980 \pm 5.47^{\mathrm{a}}$ & $41320 \pm 7.58^{\mathrm{a}}$ & \\
\hline aStatistically significant as compared to controls at $\mathrm{p}<0.01$ & & &
\end{tabular}


Fig. 1 Lead/calcium ratio and cadmium/calcium ratio in deciduous teeth
Tooth metal content

Statistically significant Celiac disease and Food allergies as compared to controls at $\mathrm{p}<0.01$.

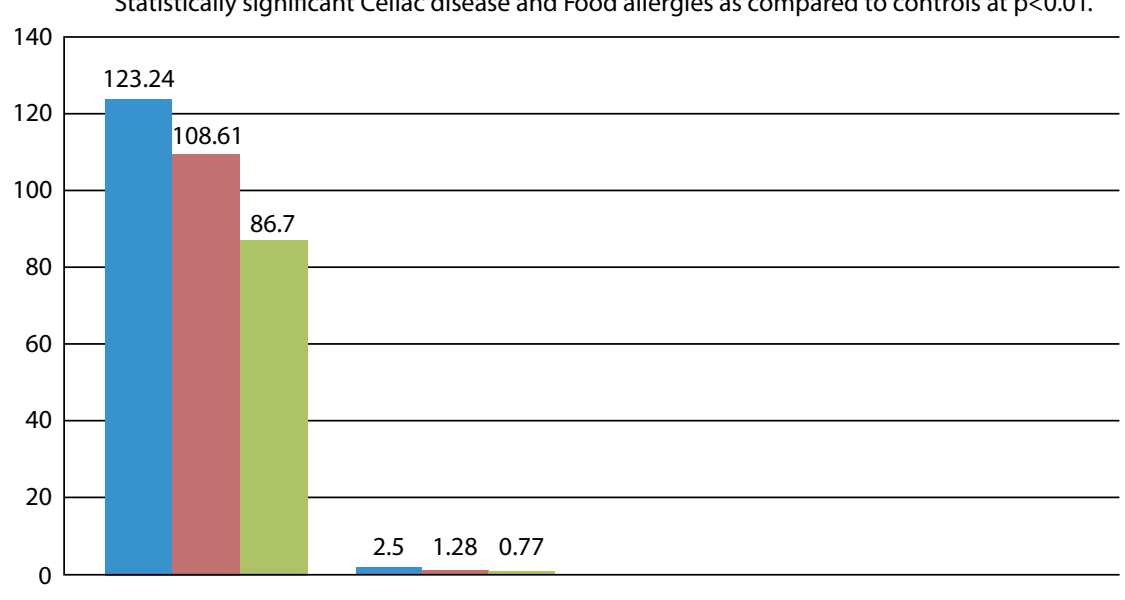

- Tooth metal content Celiac disease $\quad$ - Tooth metal content Food allergies $\quad$ Tooth metal content Control

\section{Discussion}

There are two major toxic metals, lead and cadmium, commonly present in the environment, especially in heavily industrialized regions such as Upper Silesia in Poland. In the present study it was determined that these metals preferentially accumulate in the deciduous teeth of children with celiac disease and food allergies as compared to healthy controls. In addition, the ratios of lead to calcium and cadmium to calcium showed increased levels in children with celiac disease and food allergies further indicating the accumulation of these toxic metals in the body. Because all children enrolled in the present study were from the same region, exposure to environmental pollution was comparable among all study groups. Moreover, the mothers had lived in similar environmental conditions during the gestational period. Thus, differences in the accumulation of toxic metals among the studied groups were likely to be caused by the influence of diseases and their treatment with restrictive diets and not the exposure to environmental pollutants [2].

The main source of lead and cadmium in the body ( $\sim 80 \%$ of the total content) is ingested food with $\sim 20 \%$ being inhaled through the airways. These metals can penetrate the soil via polluted air and are assimilated by vegetables. The metals are then absorbed via the food chain, in a process which is influenced by dietary factors. Absorption of toxic metals is increased by protein insufficiency, particularly by the deficiency of proteins containing sulfur amino acids. Sulfur protects cells against toxic metals and the excessive production of free radicals through inhibition of specific enzyme activities. Therefore, low sulfur/lead and sulfur/cadmium ratios in food products warrant the need for increasing consumption of proteins containing sulfur amino acids [13], mainly red meat, eggs, fish and other products such as garlic, onions, broccoli, cauliflower, black radish and radish.
Although cereal grains are poor in protein content, they contain relatively large amounts of sulfur amino acids. Thus, they provide a valuable source of sulfur for people who consume cereal grains in large amounts. In contrast, a gluten-free diet provides low levels of sulfur amino acids and therefore increases the absorption of toxic metals, which may account for increased levels of lead and cadmium found in the present study in children with celiac disease. Moreover, these children usually eat more protein products and a high consumption of protein leads to elevated excretion of calcium in urine and stool. These processes may also contribute to increased ratios of lead and cadmium to calcium as detected in the deciduous teeth in the present study.

Dietary factors may also account for decreased calcium levels in children with food allergies. Elimination of milk and dairy products from the diet of children with allergy to milk products may result in insufficient amounts of daily calcium intake. The milk replacement mixtures enriched in calcium are given mainly to children during the neonatal stage. In addition, children with allergies to egg and/or fish proteins frequently have a limited intake of sulfur amino acid [14].

Apart from polluted air and soil, a significant source of cadmium is second hand cigarette smoke. Some of the children involved in the present study were undoubtedly exposed to cigarette smoke in their homes. Studies indicate that at least 1 person in $65 \%$ of households in Poland is a cigarette smoker. Thus, children present in a closed room with a person smoking can accumulate large quantities of toxic metals, including cadmium, from the cigarette smoke [7]. Increased cadmium levels can affect normal development and interfere with the effects and bioavailability of beneficial nutrients, such as calcium, selenium, copper, iron and manganese. Excessive cadmium levels also have negative effects on activities of a variety of cellular enzymes. Cadmium accumulates mainly in the kidneys, followed by the liver, bones and 
teeth. Products which eliminate cadmium and lead from the body include vitamins $\mathrm{C}$ and $\mathrm{E}$, selenium, iron, and amino acids, such as methionine and cysteine.

In summary, this study has demonstrated that the deciduous teeth of children with celiac disease and food allergies exhibit higher accumulations of lead and cadmium than healthy children living in similar industrial environment. These findings indicate the need for dietary modifications in children treated with restrictive diets aimed to increase consumption of proteins and sulfur amino acids from the permitted foods.

\section{Open Access}

This article is distributed under the terms of the Creative Commons Attribution Noncommercial License which permits any noncommercial use, distribution, and reproduction in any medium, provided the original author(s) and source are credited.

\section{Conflict of Interest}

The authors declare that there is no conflict of interest.

\section{References}

1. Rasmusson CG, Ericsson MA. Celiac disease and mineralization disturbances of permanent teeth. Int J Paediatr Dent. 2001;11(3):179-83.

2. Malara P, Kwapuliński J, Malara B, Drugacz J. Use of element concentration ratios in the estimate of their metabolism in the teeth of people environmentally exposed to metals. Rocz Panstw Zakl Hig. 2003;54(Suppl):53-5.

3. Obuchowicz A, Orzechowska-Wylęgała B, Malara P, et al. Occurrence of selected elements in deciduous teeth of children suffering from celiac disease, food allergy and healthy children of the same age living in Upper Silesia. Polish J Environ Stud. 2006;5(15):555-8.
4. Knychalska-Karwan Z, Pawlicki R, Karwan T. Quantitative, qualitative and topographic distribution of lead, zinc, iron and copper in hard teeth tissues. Folia Histochem Cytobiol. 1985;23(1-2):21-6.

5. Kuhnlein HV, Calloway DH. Minerals in human teeth: differences between preindustrial and contemporary Hopi Indians. Am J Clin Nutr. 1977;7(30):883-6.

6. Kogut G, Fetkowska-Mielnik K. Development disorders in milk teeth enamel structure of children with celiac disease. Czas Stomat. 1991;6(44):401-4.

7. Malara P, Kwapuliński J, Drugacz J. Lead and cadmium occurrence in deciduous teeth of children who are additionally exposed to cigarette smoke in the apartments. Przegl Lek. 2004;10(61):1122-5.

8. Kalita B, Nowak P, Ślimok M, et al. Selenium plasma concentration in children with celiac disease in different stages of diagnosis. Pol Merk Lek. 2002;12(67):43-4.

9. Norska-Borówka I. Pediatry. Vol. V. Katowice: SAM; 1998.

10. Rujner J, Socha J, Wojtasik A, et al. Magnesium status in children and adolescents with celiac disease. Wiad Lek. 2001;5-6(54):277-85.

11. Kalayci AG, Kansu A, Girgin N, Kucuk O, Aras G. Bone mineral density and importance of gluten-free diet in patients with celiac disease in childhood. Pediatrics. 2001;108(5):89-95.

12. Knychalska-Karwan Z, Pawlicki R, Karwan T. Morphological changes and calcium phosphate metabolism disturbances in the teeth of patients on long-term treatment with corticosteroids (scanning microscopic and X-ray microanalyser investigation). Czas Stomat. 1982;5-6(35):249-57.

13. Mariani P, Mazzilli MC, Margutti G, et al. Coeliac disease, enamel defects and HLA typing. Acta Pediatr. 1994;83:1272-5.

14. Ziemlański S. Human feeding norms. Warszawa: PZWL; 2001. S. 314-39. 